\title{
Re-entrant tachycardia using two bypass tracts and excluding AV node in short PR interval, normal QRS syndrome
}

\author{
D. E. WARD, A. J. CAMM, AND R. A. J. SPURRELL \\ From the Department of Cardiology, St Bartholomew's Hospital, London
}

SUMMARY In patients with the short PR interval, normal QRS complex syndrome, paroxysmal tachycardias are usually the result of circus movement involving the AV node and a partial or complete AV nodal bypass. We report 2 patients with this syndrome who suffered distressing rapid paroxysms of tachycardia but in whom there was evidence of a concealed direct VA connection. In both patients, tachycardia was initiated with critical AV prolongation distal to the His bundle, in response to programmed atrial premature stimuli. The constancy of the timing of the atrial echo from the onset of the QRS complex in the presence of a varying HV interval is evidence for involvement of the ventricles in the re-entry pathway. In addition, in both patients the appearance of left bundle-branch block during tachycardia was associated with appropriate prolongation of tachycardia cycle length consistent with the presence of a direct VA connection. The short AH interval during tachycardia and the absence of critical AH prolongation suggests the participation of a rapidly conducting pathway in the anterograde limb of the tachycardia circuit.

The syndrome of short PR interval and normal QRS complex associated with paroxysmal rapid heart action was described by Lown et al. (1952). The advent of techniques of intracardiac recording and stimulation has allowed analysis of the syndrome in great detail. It is now generally accepted that the short PR interval is the result of conduction in a partial or complete AV nodal bypass (Durrer et al., 1970; Castellanos et al., 1971; Mandel et al., 1971). Intracardiac recordings in patients with this syndrome show a short $\mathrm{AH}$ interval as a result of conduction in the accessory pathway. Alternative explanations of the short PR interval include enhanced AV nodal conduction and have been enumerated by Caracta et al. (1973). The mechanism of tachycardia in the short PR interval, normal QRS complex syndrome has not been clearly elucidated. Intracardiac electrophysiological studies (Mandel et al., 1971; Denes et al., 1974) suggest that the most common mechanism is associated with block in the rapidly conducting pathway and critical prolongation of the AH interval allowing re-entry towards the atrium in the fast extranodal pathway. In the 2 patients described in this report a different mechanism was evident.

\section{Patients and methods}

A 63-year-old man (case 1) was admitted to hospital in March 1977 for investigation of paroxysmal palpitation which he had experienced for 12 years. Acute attacks had failed to respond reliably to intravenous propranolol or verapamil and in recent months he had required DC conversion to restore sinus rhythm. Oral therapy which had included propranolol and disopyramide reduced the frequency of attacks. Physical examination and routine investigations were normal. The surface electrocardiogram showed a PR interval of $0.11 \mathrm{~s}$ during sinus rhythm and a normal QRS complex.

The second patient (case 2), a 26-year-old man suffered rapid paroxysms of palpitation since the age of 12 years. Various medications including digoxin, procainamide, propranolol, and verapamil had failed to control attacks. In the 2 years before investigation he had had several attacks requiring DC conversion to sinus rhythm. On other occasions intravenous verapamil was administered and successfully terminated the tachycardia only once. The patient was admitted for investigation in June 1977. Physical examination and routine investigations were normal. The surface electrocardiogram revealed a PR interval of $0.12 \mathrm{~s}$ and normal QRS complexes. 
Both patients were studied in the postabsorptive non-sedated state. All medications were stopped 4 days before study. Four pacing electrodes were introduced into the right femoral vein under local anaesthetic and were positioned fluoroscopically in the apex of the right ventricle, against the septal leaflet of the tricuspid valve and in the high right atrium. In case 1 an additional electrode catheter was introduced via the left basilic vein and positioned in the coronary sinus. All intracardiac signals were filtered between 50 and $700 \mathrm{~Hz}$ and recorded simultaneously with surface leads I, aVF, and V1 on an Elema Mingograph at $100 \mathrm{~mm} / \mathrm{s}$, with time markings at 1-second intervals.

Stimulation was performed using a Devices $\mathbf{4 2 7 0}$ isolated stimulator with $1.5 \mathrm{~ms}$ square wave pulses delivered at approximately twice the diastolic threshold.

\section{DEFINITIONS}

The following abbrevations, terms, and definitions are used throughout the text-

$A_{1}, H_{1}, V_{1}$ the atrial, $H i s$ bundle, and ventricular electrogram during basic atrial pacing.

$A_{2}, H_{2}, V_{2}$ the atrial, $H i s$ bundle, and ventricular electrograms produced by premature atrial stimulation.

$\mathrm{AH}$ the interval between the intrinsic deflection of the atrial electrogram and the intrinsic deflection of the $\mathrm{His}$ bundle electrogram on the His bundle electrode.
HV

$\mathrm{VA}^{\prime}$

\section{Results}

\section{CASE 1}

At electrophysiological study during sinus rhythm the AH interval was $60 \mathrm{~ms}$ with an $\mathrm{HV}$ interval of $35 \mathrm{~ms}$. During incremental atrial pacing the $\mathrm{AH}$ interval increased from $60 \mathrm{~ms}$ at a cycle length of $610 \mathrm{~ms}$ to $80 \mathrm{~ms}$ at a cycle length of $375 \mathrm{~ms}$. Programmed atrial premature stimuli were delivered throughout electrical diastole. Fig. 1a shows the anterograde conduction curve constructed by plotting the $\mathrm{H}_{1} \mathrm{H}_{2}$ and $\mathrm{V}_{1} \mathrm{~V}_{2}$ intervals against the coupling interval of the premature stimulus, $\mathrm{A}_{1} \mathrm{~A}_{2}$. $\mathrm{A}_{1} \mathrm{~A}_{2}$ values between 610 and $385 \mathrm{~ms}$ produced a small prolongation of the $\mathrm{H}_{1} \mathrm{H}_{2}$ interval. As the coupling interval was shortened from $385 \mathrm{~ms}$ to $310 \mathrm{~ms}$ prolongation of the $\mathrm{H}_{2} \mathrm{~V}_{2}$ interval occurred and left bundle-branch block appeared. Within this range of coupling intervals the $\mathrm{A}_{2} \mathrm{H}_{2}$ interval increased by only $10 \mathrm{~ms}$ to $90 \mathrm{~ms}$.

Fig. 2a shows initiation of tachycardia at a coupling interval of $310 \mathrm{~ms}$. The $\mathrm{H}_{2} \mathrm{~V}_{2}$ interval increased to $85 \mathrm{~ms}$ at this coupling interval. At all
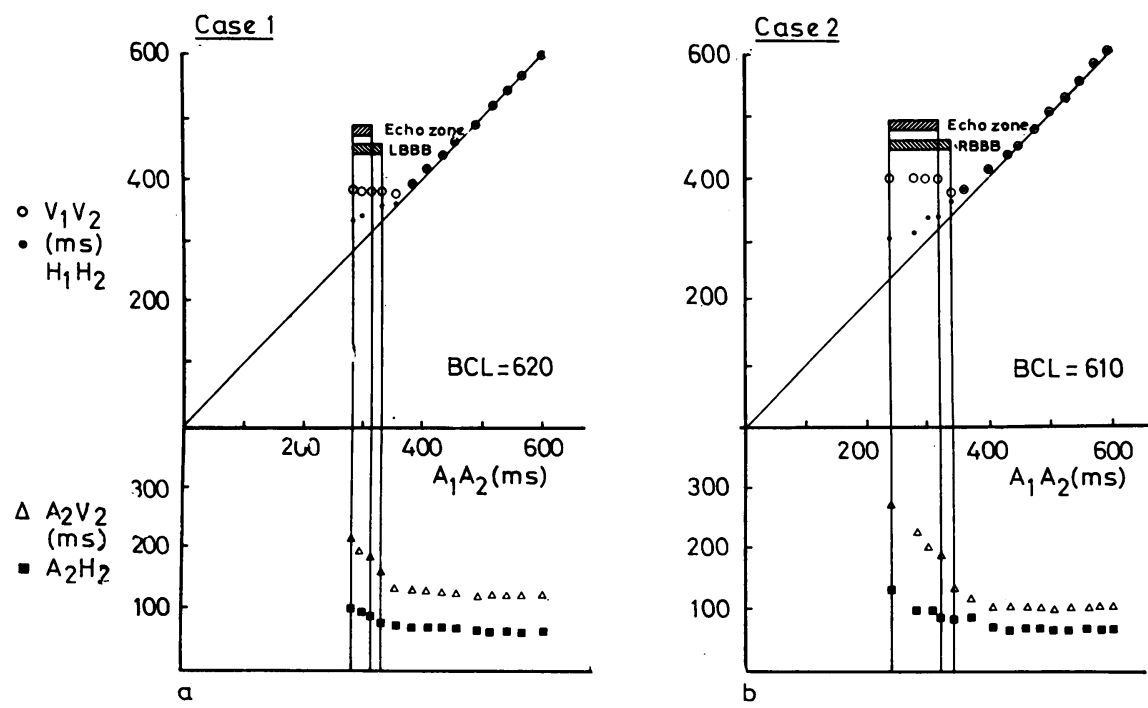

Fig. 1 Anterograde conduction curves in cases 1 and 2. 


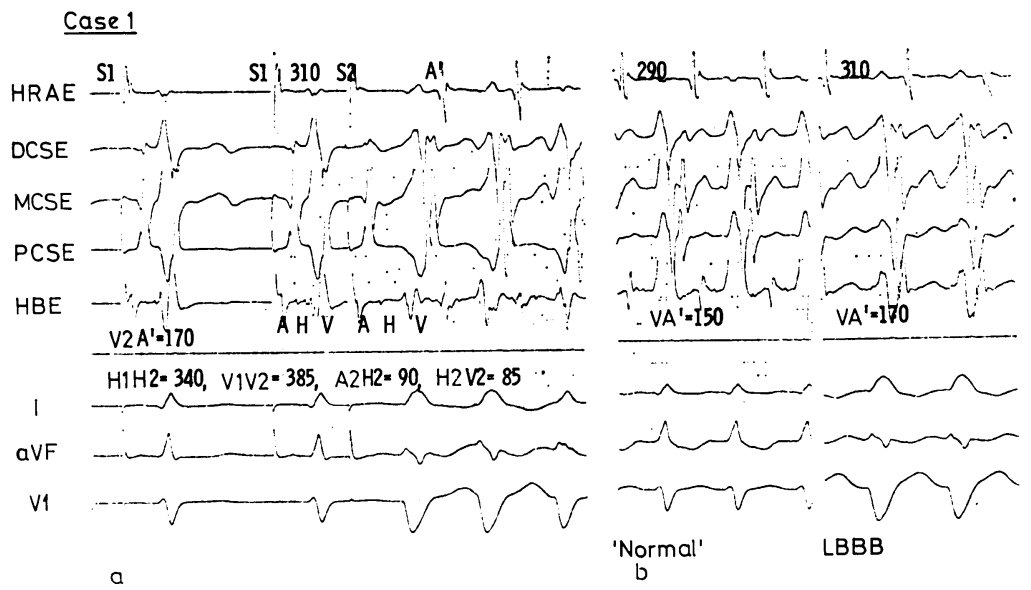

Fig. 2 (a) Initiation of tachycardia by premature atrial stimulation $\left(S_{2}\right)$.

(b) Tachycardia with normal QRS complexes and a cycle length of $290 \mathrm{~ms}$ compared with tachycardia with left bundle-branch block and cycle length of $310 \mathrm{~ms}$.

HRAE, high right atrial electrogram; DCSE, distal coronary sinus electrogram;

MCSE, mid-coronary sinus electrogram; PCSE, proximal coronary sinus electro-

gram; HBE, His bundle electrogram; I, aVF, VI, surface electrocardiographic leads.

intervals of $A_{1} A_{2}$ which resulted in left bundlebranch block and an atrial echo or sustained tachycardia the $\mathrm{V}_{2} \mathrm{~A}^{\prime}$ interval remained between 165 and $170 \mathrm{~ms}$ despite variations in the $\mathrm{A}_{2} \mathrm{H}_{2}$ and $\mathrm{H}_{2} \mathrm{~V}_{2}$ intervals. The same $\mathrm{V}_{2} \mathrm{~A}^{\prime}$ interval was observed during tachycardia. Narrow complex tachycardia was not initiated by a single atrial premature stimulus. During tachycardia earliest activation of the atria occurred on the proximal coronary sinus electrogram. A single ventricular stimulus during tachycardia $15 \mathrm{~ms}$ before the onset of the His bundle potential was conducted retrogradely, resetting the atrial electrogram without disturbing the His bundle depolarisation or altering the atrial activation sequence. This is shown in Fig. 3. Appropriately timed ventricular stimuli during tachycardia resulted in conversion of the left bundlebranch block tachycardia to narrow complex tachycardia. When this occurred the cycle length of tachycardia was shortened by an amount corresponding to the shortening of the $\mathrm{VA}^{\prime}$ interval (Fig. 2b). Fig. 4a shows narrow complex tachycardia with a short $\mathrm{A}^{\prime} \mathrm{H}$ interval of $55 \mathrm{~ms}$ and normal $\mathrm{HV}$ interval. Termination of both narrow and broad complex tachycardia was reliably achieved by rapid atrial pacing or double ventricular stimuli. Programmed ventricular premature stimuli after a regular pacing sequence resulted in constancy of retrograde conduction time with earliest activation of the atria on the proximal coronary sinus electrogram.
CASE 2

During sinus rhythm the AH interval was $65 \mathrm{~ms}$ and HV $35 \mathrm{~ms}$. Incremental atrial pacing prolonged the $\mathrm{AH}$ interval from $65 \mathrm{~ms}$ at a cycle length of $610 \mathrm{~ms}$ to $90 \mathrm{~ms}$ at a paced cycle length of $375 \mathrm{~ms}$. The HV interval remained unchanged. The $\mathrm{H}_{1} \mathrm{H}_{2}$ and $V_{1} V_{2}$ intervals resulting from progressively shortened $A_{1} A_{2}$ values are shown in Fig. $1 b$.

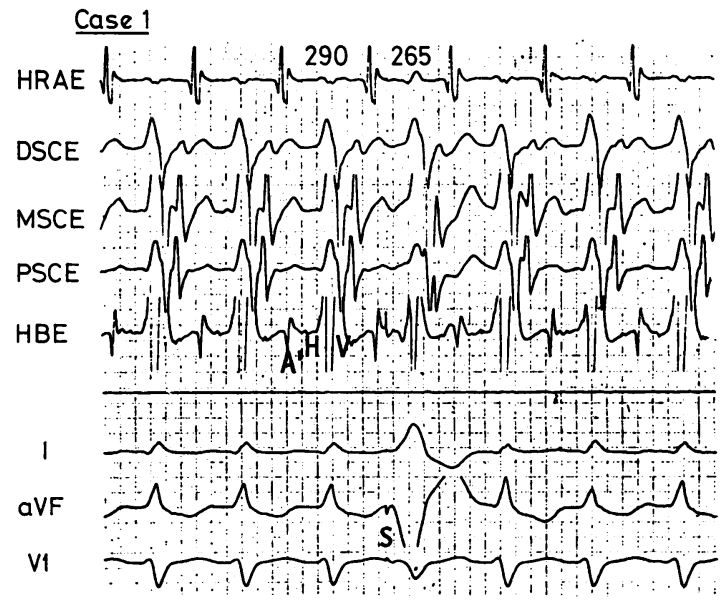

Fig. 3 Premature ventricular stimulation during tachycardia resulting in exact atrial capture. $S$, stimulus artefact. 


\section{Case 1}

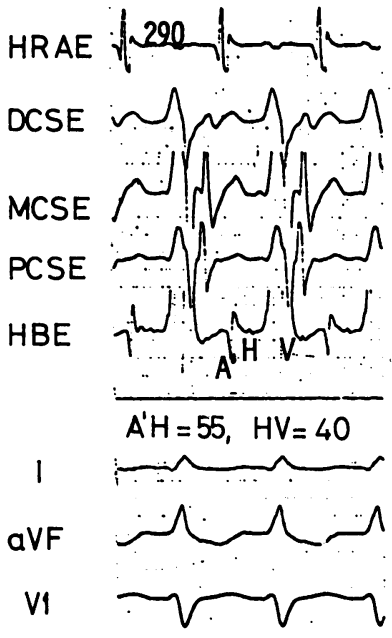

$\mathbf{a}$

\section{Case 2}

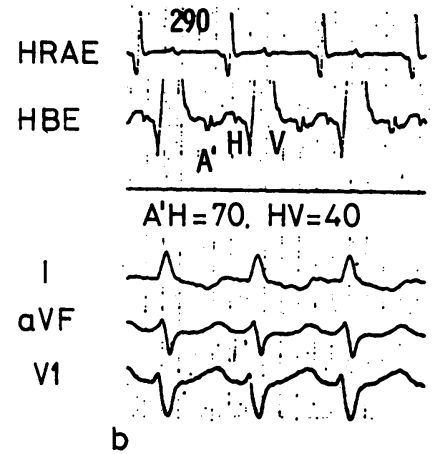

Fig. 4 Tachycardia in case $1(a)$ and case $2(b)$ demonstrating short $A H$ ir.terval.
Values of $A_{1} A_{2}$ between 610 and $360 \mathrm{~ms}$ caused minimal prolongation of the $\mathrm{A}_{2} \mathrm{H}_{2}$ intervals. Earlier premature stimuli resulted in gradual prolongation of the $\mathrm{H}_{2} \mathrm{~V}_{2}$ interval. Fig. 5 compares a premature stimulus at $440 \mathrm{~ms}$ with a stimulus at $320 \mathrm{~ms}$ which resulted in prolongation of the $\mathrm{H}_{2} \mathrm{~V}_{2}$ interval to $105 \mathrm{~ms}$, right bundle-branch block, and initiation of tachycardia. Shorter coupling intervals resulted in similar responses. At all coupling intervals which produced atrial echo beats or sustained tachycardia the $\mathrm{V}_{2} \mathrm{~A}^{\prime}$ interval remained constant at 210 to $215 \mathrm{~ms}$, though the $\mathrm{H}_{2} \mathrm{~V}_{2}$ interval varied from 105 to 135 $\mathrm{ms}$ and the $\mathrm{A}_{2} \mathrm{H}_{2}$ interval varied minimally.

Appropriately timed single ventricular stimuli during right bundle-branch block tachycardia resulted in conversion to narrow complex tachycardia without change in cycle length. On one occasion tachycardia with left bundle-branch block was precipitated by a non-programmed stimulus. The $\mathrm{VA}^{\prime}$ interval increased by $30 \mathrm{~ms}$ with a corresponding increase in cycle length. Fig. 6 shows all 3 varieties of tachycardia. Right bundle-branch block and normal complex tachycardia both had a cycle length of $290 \mathrm{~ms}$ with $\mathrm{VA}^{\prime}$ intervals of $210 \mathrm{~ms}$, whereas left bundle-branch block tachycardia had a cycle length of $320 \mathrm{~ms}$ and $\mathrm{VA}^{\prime}$ of $240 \mathrm{~ms}$. Exact capture of the atria by ventricular stimulation could not be achieved presumably because right ventricular apical stimuli were too remote from the tachycardia circuit. Fig. $4 \mathrm{~b}$ shows a short $\mathrm{A}^{\prime} \mathrm{H}$ interval of $70 \mathrm{~ms}$ and $\mathrm{HV}$ of $\mathbf{4 0} \mathrm{ms}$ during narrow complex tachycardia. Termination of tachycardia was reliably achieved by rapid atrial pacing or appropriately timed double ventricular stimuli. Programmed ventricular premature stimuli resulted in constancy of retrograde conduction time.

\section{Case 2}
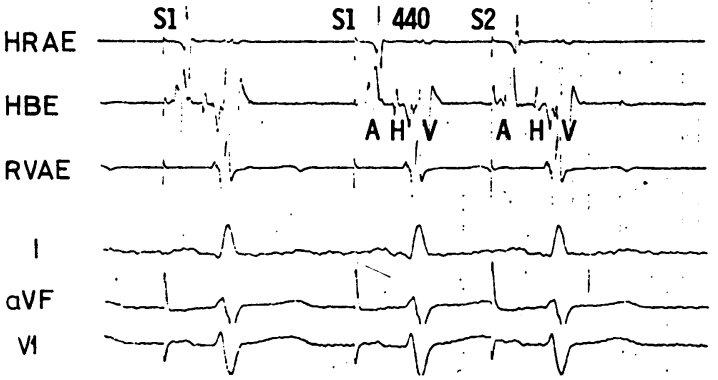

$\mathrm{H}_{1} \mathrm{H}_{2}=450, \mathrm{~V}_{1} \mathrm{~V}_{2}=450, \mathrm{~A}_{2} \mathrm{H}_{2}=85, \mathrm{H}_{2} \mathrm{~V}_{2}=35$
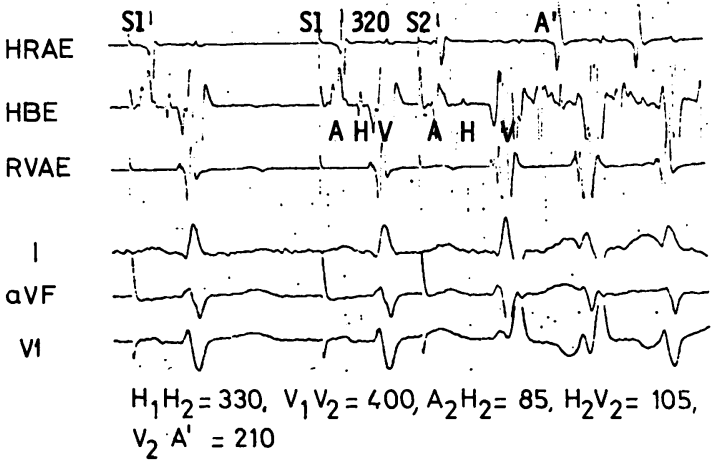

Fig. 5 Atrial premature stimuli $\left(S_{2}\right)$ in case 2 at coupling intervals of $440 \mathrm{~ms}$ (upper panel) and $320 \mathrm{~ms}$ (lower panel). RVAE, right ventricular apical electrogram. 


\section{Case 2}

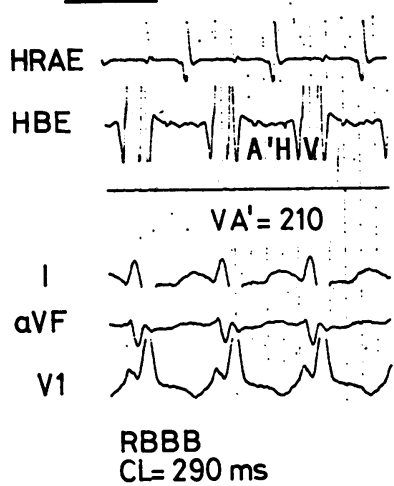

\section{Discussion}

The presence of a short PR interval and narrow QRS complex on the surface electrocardiogram is frequently associated with paroxysmal tachycardias (Lown et al., 1952; Castellanos et al., 1971). In recent years electrophysiological studies have shown abnormal responses to atrial pacing in many of these patients. In normal subjects, incremental atrial pacing or programmed atrial premature stimuli at progressively shorter coupling intervals results in smooth prolongation of $\mathrm{AH}$ conduction (Wit et $a l ., 1970)$. In patients with the short $P R$ interval, normal QRS complex syndrome this prolongation of the AH interval may be attenuated or absent (Castellanos et al., 1971; Bisset et al., 1973; Caracta et al., 1973; Denes et al., 1974; Neuss et al., 1975a).

This response has been attributed to complete or partial bypass of the AV node by accessory tracts (James, 1961) inserting into the lower AV junction. The existence of a bypass tract has been proven histologically in one patient with this syndrome (Brechenmacher et al., 1974).

In both patients described here the $\mathrm{AH}$ interval increased minimally in response to incremental atrial pacing and programmed atrial premature stimuli, suggesting that conduction to the ventricles was not occurring in the normal delaying pathways. Conduction in a 'fast pathway' with short functional refractoriness such as an atrionodal bypass, at earlier coupling intervals of atrial premature stimuli results in preactivation of the $\mathrm{AV}$ junction. The short AH functional refractoriness (Bisset et al., 1975) may result in prolongation of the $\mathrm{H}_{2} \mathrm{~V}_{2}$ interval and bundle-branch block at early coupling intervals (Coumel et al., 1972; Seipel et al., 1976). Fig. 7 is a diagrammatic representation of this mechanism.

Dual intranodal pathways have been demonstrated in animals and in patients with intra-AV nodal re-

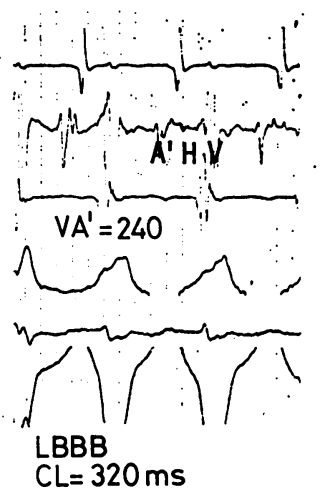

Fig. 6 Three forms of tachycardia in case 2. entry (Moe and Mendez, 1966; Goldreyer and Damato, 1971; Denes et al., 1973). A similar phenomenon may be seen in patients with the short PR interval, normal QRS complex syndrome and is thought to represent block in the fast intranodal or extranodal pathway (Denes et al., 1974). In patients with duality of intranodal conduction onset of tachycardia during programmed atrial stimulation is associated with critical AH delay. In the patients described here, no sudden prolongation of the $\mathrm{AH}$ interval occurred and the major delay occurred distal to the site of His bundle recording. These observations suggest continued anterograde conduction in the fast pathway and the lack of effect of verapamil on tachycardia cycle length and $\mathrm{AH}$ interval, lends credence to this hypothesis. With critical AV conduction delay atrial echo beats or sustained tachycardia is initiated with return to the atria either via the AV node or a concealed direct VA connection.

The participation of a concealed direct VA connection (Spurrell et al., 1974a; Tonkin et al., 1975)

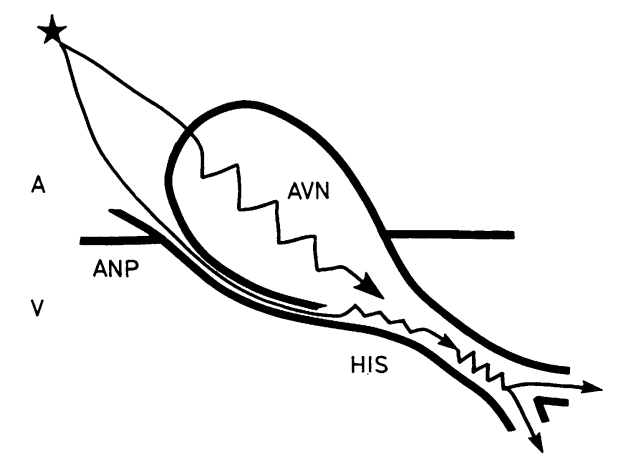

Fig. 7 Diagram of mechanism of AV junctional preexcitation by atrial premature stimulus (star). $A V N$, atrioventricular node; $A N P$, atrionodal pathway; $H$ is, His bundle; $A$, atrium; $V$, ventricles. 


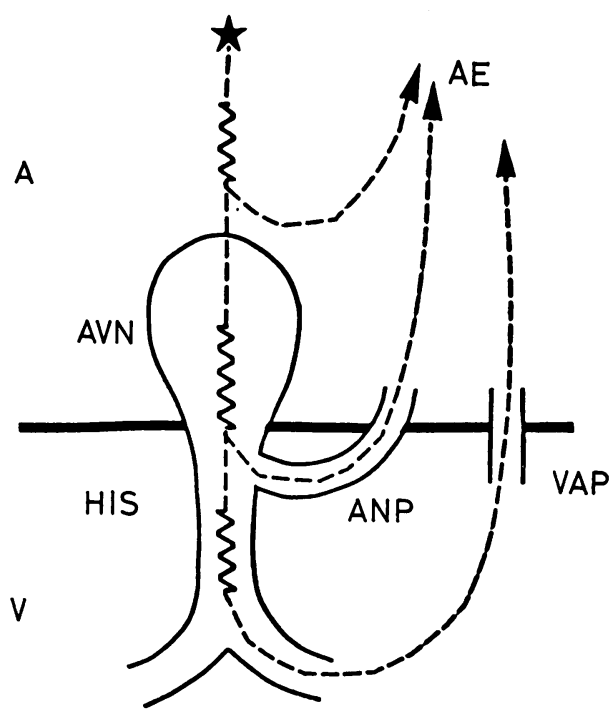

Fig. 8 An atrial premature stimulus (star) may result in anterograde conduction delay sufficient to allow reentry to the atrium $(A E)$. Such re-entry may involve an atrionodal pathway $(A N P)$ or a direct ventriculoatrial pathway $(V A P)$. Critical conduction delay above the $H$ is bundle associated with a constant $H-A E$ interval suggests re-entry within the $A V$ node or via an atrionodal pathway. Delay below the site of the His bundle with a constant $V-A E$ interval suggests re-entry via a direct $V A$ pathway.

in the tachycardia circuit is suggested by the timing of the atrial echo beat. The constancy of the $\mathrm{V}_{2} \mathrm{~A}^{\prime}$ interval in the presence of a varying $\mathrm{H}_{2} \mathrm{~V}_{2}$ interval makes it unlikely that the re-entrant pathway is located entirely above the His bundle and implies the participation of the ventricles in the tachycardia circuit. Intra-AV nodal re-entry or re-entry in an atrionodal pathway results in nearly constant $\mathrm{H}_{2} \mathrm{~A}^{\prime}$ intervals. If, however, the $\mathrm{H}_{2} \mathrm{~V}_{2}$ is constant no conclusion can be drawn about the site of re-entry. Fig. 8 summarises these concepts.

The appearance of atrial echoes with critical HV conduction delay has been described previously (Lozano et al., 1973; Varghese et al., 1974; Neuss et al., 1975b). Both Lozano et al. (1973) and Varghese et al. (1974) interpreted their findings as indicative of a combination of intraventricular and intra AV nodal re-entry. However, a concealed, direct, VA connection could not be excluded in their patients. The short AH in response to programmed atrial premature beats and the lack of $\mathrm{AH}$ prolongation with increasing prematurity of atrial stimulation suggests the presence of a fast anterograde pathway in the patient reported by Lozano et al. (1973). Neuss et al. (1975b) report a patient with similar findings to the patients described here. They also observed constancy of the $\mathrm{V}_{2} \mathrm{~A}^{\prime}$ interval in the presence of an increasing $\mathrm{H}_{2} \mathrm{~V}_{2}$ interval in response to premature atrial stimuli delivered during sinus rhythm. This observation was regarded as proof of involvement of the ventricles within the re-entrant circuit. No comment was made concerning the mechanism of critical conduction delay. The absence of atrial echo beats or tachycardia at later coupling intervals of $\mathbf{A}_{2}$ is probably related to limiting atrial refractoriness at the time of retrograde activation of the VA pathway (Pritchett et al., 1977), or alternatively to concealed anterograde invasion of the VA pathway during atrial stimulation (Zipes et al., 1974).

Additional evidence for an accessory concealed VA connection in our patients was provided by the following observations.

(1) In both patients the appearance of left bundle-branch block during tachycardias was associated with an increase in $\mathrm{VA}^{\prime}$ conduction and tachycardia cycle length (Coumel and Attuel, 1974; Pritchett et al., 1976; Spurrell et al., 1974b).

(2) In case 1 coronary sinus recordings revealed early activation of the low left atrium near the proximal coronary sinus during tachycardia. This does not prove that retrograde activation is via a direct AV pathway since retrograde conduction in an atrionodal pathway may produce similar eccentric atrial activation. However, a ventricular premature stimulus, delivered $15 \mathrm{~ms}$ before the His bundle potential, conducted retrogradely with exact atrial capture and identical atrial activation sequence. Retrograde conduction in an atrionodal pathway would be impossible in these conditions and the retrograde limb of the re-entrant circuit, is therefore, a direct VA pathway (Sellers et al., 1976).

The coexistence of anomalous atrionodal and atrioventricular pathways has been described previously (Coumel et al., 1971, 1972; Neuss et al., 1975b; Zipes et al., 1974; Castellanos et al., 1975) and unusual re-entry mechanisms may result from these combinations. The mechanism of re-entry in our patients is dependent on an interaction between two functionally abnormal pathways. Conduction delay at infra-Hisian level occurs as a result of preactivation of the AV junction and retrograde conduction occurs when critical delay is sufficient to allow re-entry in the VA pathway and atrial myocardium.

In the patients described by Lozano and his colleagues (1973) tachycardia was initiated in the presence of a short AH interval which persisted during sustained tachycardia. These observations suggest the incorporation of a partial or complete AV nodal bypass tract in the anterograde limb of the re-entrant circuit. Re-entrant circuits utilising an 
anterograde fast pathway bypassing the $\mathrm{AV}$ node and a retrograde direct VA pathway may result in rapid, distressing tachycardias unresponsive to therapy directed towards the AV node itself, and in these cases verapamil was not effective. Detailed electrophysiological studies are required to define the tachycardia mechanism in these patients.

\section{References}

Bisset, J. K., de Soyza, N., Kane, J. J., and Murphy, M. L. (1975). Altered refractory periods in patients with short $P R$ intervals and normal QRS complex. American fournal of Cardiology, 35, 487-491.

Bisset, J. K., Thompson, A., de Soyza, N., and Murphy, M. L. (1973). Atrioventricular conduction in patients with short PR intervals and normal QRS complexes. British Heart fournal, 35, 123-127.

Brechenmacher, C., Laham, J., Iris, L., Gerbaux, A., and Lenègre, J. (1974). Étude histologique des voies anormales de conduction dans un syndrome de Wolff-ParkinsonWhite et dans un syndrome Lown-Ganong-Levine. Archives des Maladies du Coeur et des Vaisseaux, 67, 507-520.

Caracta, A. R., Damato, A. N., Gallagher, J. J., Josephson, M. E. I., Varghese, P. J., Lau, S. H., and Westura, E. F. (1973). Electrophysiological studies in the syndrome of short P-R interval, normal QRS complex. American fournal of Cardiology, 31, 245-253.

Castellanos, A., Agha, A. S., Befeler, B., and Myerburg, K. (1975). Double accessory pathways in Wolff-ParkinsonWhite syndrome. Circulation, 51, 1020-1025.

Castellanos, A., Castillo, C. A., Agha, A. S., and Tessler, M. (1971). His bundle electrograms in patients with short P-R intervals, narrow QRS complexes and paroxysmal tachycardias. Circulation, 43, 667-678.

Coumel, P., and Attuel, P. (1974). Reciprocating tachycardia in overt and latent pre-excitation. European fournal of Cardiology, 1, 423-436.

Coumel, P., Wayneberger, M., Fabiato, A., Slama, R., Aigueperse, J., and Bouvrain, Y. (1972). Wolff-ParkinsonWhite syndrome. Problems in evaluation of multiple accessory pathways and surgical therapy. Circulation, 45, 1216-1230.

Coumel, P., Wayneberger, M., Garnier, J. C., Slama, R., and Bouvrain, Y. (1971). Syndrome de préexcitation ventriculaire associant $P-R$ court et onde delta, sans élargissment de QRS: (a propos de trois cas de syndrome de WPW à complexes fins). Archives des Maladies du Coeur et des Vaisseaux, 64, 1234-1255.

Denes, P., Wu, D., Dhingra, R. C., Chuquimia, R., and Rosen, K. M. (1973). Demonstration of dual A-V nodal pathways in patients with paroxysmal supraventricular tachycardia. Circulation, 48, 549-555.

Denes, P., Wu, D., and Rosen, K. M. (1974). Demonstration of dual A-V pathways in a patient with the Lown-GanongLevine syndrome. Chest, 65, 343-346.

Durrer, D., Schuilenburg, R. M., and Wellens, H. J. J. (1970). Pre-excitation revisited. American fournal of Cardiology', 25, 690-697.

Goldreyer, B. N., and Damato, A. N. (1971). The essential role of atrioventricular conduction delay in the initiation of paroxysmal supraventricular tachycardia. Circulation, 43, 679-687.

James, T. N. (1961). The morphology of the human atrioventricular node, with remarks pertinent to its electrophysiology. American Heart fournal, 62, 756-771.

Lown, B., Ganong, W. F., and Levine, S. A. (1952). The syndrome of short P-R interval, normal QRS complex and paroxysmal rapid heart action. Circulation, 5, 693-706.

L.ozano, J., Mandel, W. J., Hayakawa, H., Shine, K. I., and Eber, L. M. (1973). Re-entrant tachycardia: participation of the distal A-V conduction system. Chest, 63, 23-34.

Mandel, W. J., Danzig, R., and Hayakawa, H. (1971). LownGanong-Levine syndrome. Circulation, 44, 696-708.

Moe, G. K., and Mendez, C. (1966). The physiologic basis of reciprocal rhythm. Progress in Cardiovascular Diseases, 8, 461-482.

Neuss, H., Nowak, F., and Schlepper, M. (1975a). Analyse der A-V Uberleitung bei kurzer P-Q Zeit. In His-Bündel Elektrographie, p. 153. Ed. by L. Seipel, F. Loogen, and A. Both. Schattauer Verlag, Stuttgart.

Neuss, H., Schlepper, M., and Thormann, J. (1975b). Analysis of re-entry mechanisms in three patients with concealed Wolff-Parkinson-White syndrome. Circulation, 51, 75-81.

Pritchett, E. L. C., Gallagher, J. J., and Scheinman, M. (1977). Determinants of the echo zone in patients with reciprocating tachycardia and the Wolff-Parkinson-White syndrome (abstract). American Fournal of Cardiology, 39, 319.

Pritchett, E. L. C., Tonkin, A. M., Dugan, F. A., Wallace, A. G., and Gallagher, J. J. (1976). Ventriculo-atrial conduction time during reciprocating tachycardia with intermittent bundle branch block in Wolff-Parkinson-White syndrome. British Heart fournal, 38, 1058-1064.

Seipel, L., Breithardt, G., and Both, A. (1976). Atrioventricular (A-V) and ventriculoatrial (VA) conduction pattern in patients with short $P R$ interval and normal $Q R S$. In Cardiac Pacing-Diagnostic and Therapeutic Tools, p. 152. Ed. by B. Luderitz. Springer-Verlag, Berlin.

Sellers, T. D., Jr., Gallagher, J. J., Cope, G. D., Tonkin, A. M., and Wallace, A. G. (1976). Retrograde atrial preexcitation following premature ventricular beats during reciprocating tachycardia in the Wolff-Parkinson-White syndrome. European fournal of Cardiology, 4, 283-294.

Spurrell, R. A. J., Krikler, D. M., and Sowton, E. (1974a). Concealed bypasses of the atrioventricular node in patients with paroxysmal supraventricular tachycardia revealed by intracardiac electrical stimulation and Verapamil. American fournal of Cardiology, 33, 590-595.

Spurrell, R. A. J., Krikler, D. M., and Sowton, E. (1974b). Retrograde invasion of the bundle branches producing aberration of the QRS complex during supraventricular tachycardia studied by programmed electrical stimulation. Circulation, 50, 487-495.

Tonkin, A. M., Gallagher, J. J., Svenson, R. H., Wallace, A. G., and Sealy, W. C. (1975). Anterograde block in accessory pathways with retrograde conduction in reciprocating tachycardia. European fournal of Cardiology, 3, 143-152.

Varghese, P. J., Damato, A. N., Caracta, A. R., Gallagher, J. J., Josephson, M. E., and Lau, S. H. (1974). Intraventricular conduction delay as a determinant of atrial echo beats. Circulation, 49, 805-810.

Wit, A. L., Weiss, M. B., Berkowitz, W. D., Rosen, K., Steiner, C., and Damato, A. N. (1970). Patterns of atrioventricular conduction in the human heart. Circulation Research, 27, 345-359.

Zipes, D. P., DeJoseph, R. L., and Rothbaum, D. A. (1974). Unusual properties of accessory pathways. Circulation, 49, 1200-1211.

Requests for reprints to Dr D. E. Ward, Department of Cardiology, St Bartholomew's Hospital, West Smithfield, London EC1A 7BE. 